\title{
AIRWAY PRESSURES AND VENTILATION IN EMPHYSEMA DURING AND AFTER RESPIRATORY INFECTIONS
}

BY

\author{
R. S. JONES \\ From St. Mary Abbots Hospital, London, and the Pneumoconiosis Research Unit, \\ Llandough Hospital, Penarth, Glamorgan
}

(RECEIVED FOR PUBLICATION FEBRUARY 13, 1957)

Recent work has led to a fuller knowledge of the way in which the respiratory mechanism fails in patients with advanced bronchitis and emphysema (Donald and Christie, 1949; Prime and Westlake, 1954; Westlake, 1954). In the later phases of the disease, a point is reached at which there is anoxia and hypercapnia which is the result of failure to maintain an adequate alveolar ventilation. Ultimately, the effectiveness of pulmonary ventilation depends upon the power of the muscles of respiration to supply the force required to overcome the resistances of the airways to gas flow and the lung tissues to deformation. Ventilation becomes impaired if this power is lacking or the resistances are increased, as they are for example during exacerbations of respiratory infection. An indirect measure of the respiratory muscular force can be obtained from the pressure developed at the mouth during brief interruption of the airway. The airway interrupter method has been used to measure fluctuations in this pressure during and after exacerbations of respiratory infection in order to obtain more information $a b o u t$ the mechanism of respiratory failure.

The relationship between dyspnoea and the force exerted during respiration has been examined by several worke rs (Christie, 1953 ; Marshall, Stone, and Christie, 1954). The latter authors suggested that the sensation of breathlessness is caused by the amplitude of the intrathoracic pressure changes w h i ch accompany inspiration. This paper reports an attempt to correlate dyspnoea with the magnitude of the pressure developed at the mouth during brief airway interruption. Measure- $\overrightarrow{-}$ ments of pressure and ventilation were made in $\vec{N}$ patients with bronchitis and emphysema duringo and after exacerbations of respiratory infection ${ }_{-}$ and in normal subjects.

\section{MeTHODS}

APParatus.-Pressures were measured at the mouth $\overrightarrow{0}$ during natural breathing by the method of airway ${ }_{\infty}$ interruption (Neegaard and Wirz, 1927 ; Vuilleumier, 1944 ; Otis and Proctor, 1948). An apparatus waso designed to produce interruption at the points of maximum velocity of airflow in each phase of theo respiratory cycle. The equipment was mounted on a

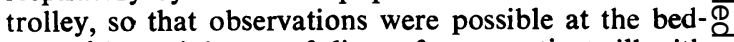
side with a minimum of discomfort to patients ill with $\overrightarrow{\vec{P}}$ acute respiratory infections.

In the apparatus shown diagrammatically in Figs. $1 \frac{3}{3}$ and 2 , the interrupter, $I$, was placed in the tube between the patient and the spirometer, $S$, which was of the Bernstein type (Bernstein, D'Silva, and

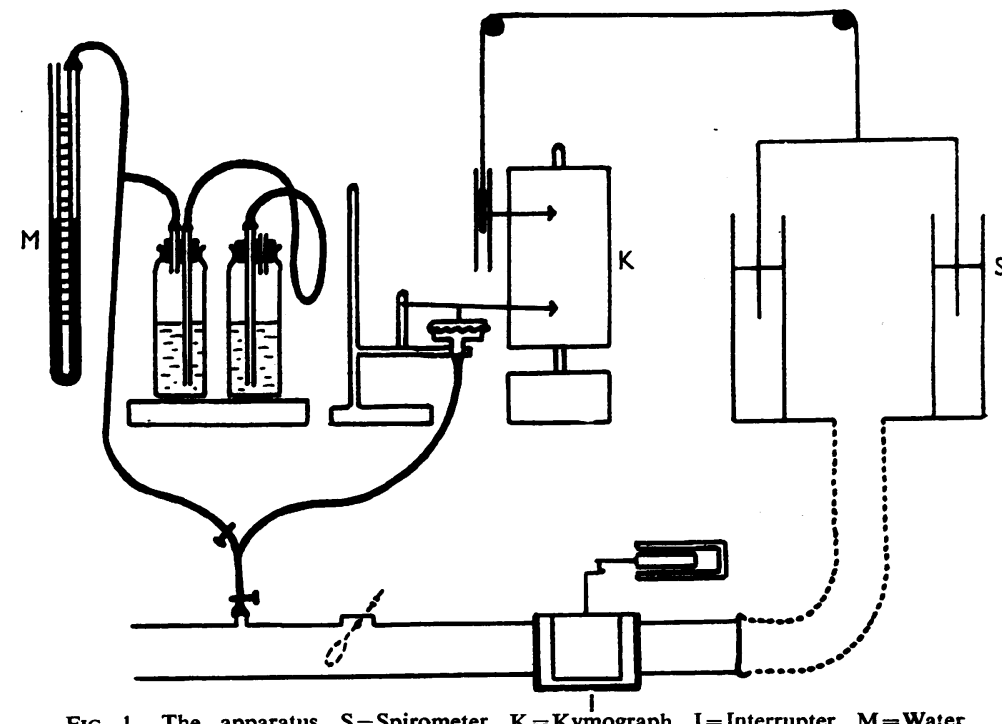

FIG. 1. The apparatus. $S=$ Spirometer. $K=$ Kymograph. $I=$ Interrupter. $M=$ Water manometer. 


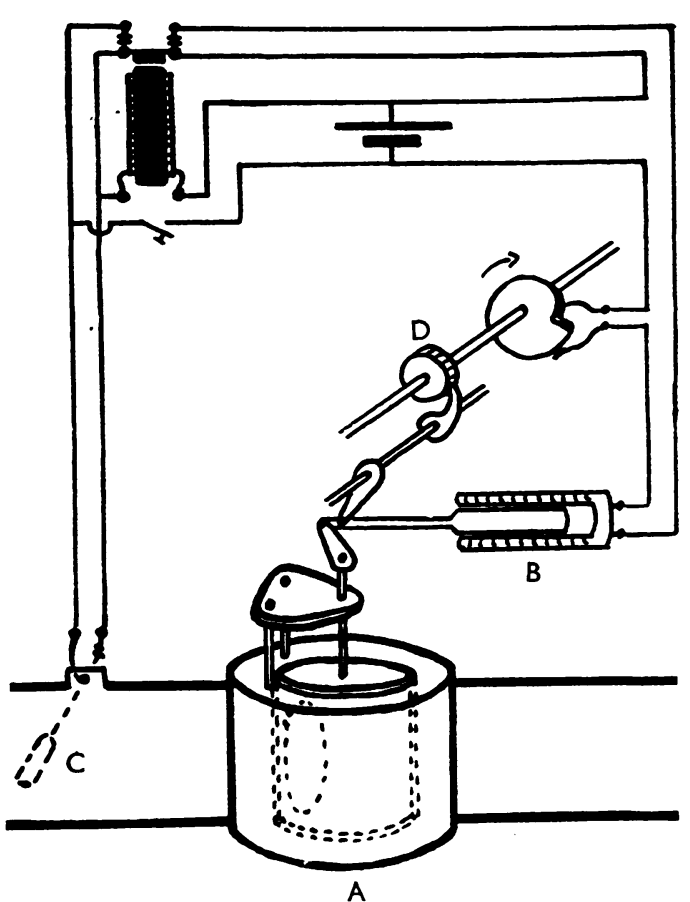

Fig. 2.-Interrupter and electrical circuit. $A=$ Interrupter (barrel tap with hole in core). $\quad B=$ Solenoid. $\quad C=A$ light vane suspended in the airway, adjusted to produce interruption at maximum rate of airflow. $\mathbf{D}=$ Clockwork-driven mechanism to control duration of interruption.

Mendel, 1952). Volume changes were recorded on a kymograph, $\mathbf{K}$. The interrupter was a barrel tap, A, (Fig. 2), with a 1 in. diameter hole in the core. Interruption was produced by rotation of the core through $90^{\circ}$ by a solenoid, B. A light vane, C, in the airstream controlled, through an adjustable contact, the flow rate necessary to close the tap. The clockwork mechanism, D, controlled the period during which the tap remained closed. This was adjusted so that the duration of interruption was $0.25 \mathrm{sec}$. Pressures were recorded with a tambour. The response was complete in less than $0.1 \mathrm{sec}$. The dead space of the apparatus was approximately $300 \mathrm{ml}$. Each figure for inspiratory and expiratory pressure in the tables is the mean value of six to eight observations. Fig. 3 is a reproduction of a volume and pressure record. All tests were carried out with the patient in the sitting position. Exercise tests were made on a bicycle ergometer with an adjustable rim brake.

Duplicate observations of pressure on two severely disabled subjects were made: (1) at rest, (2) during exercise to just detectable dyspnoea, and (3) after exercise to the limit of tolerance. Inspiratory and expiratory pressure differences were of the same order of magnitude in both subjects at rest and during exercise. A maximum difference of $2 \mathrm{~cm}$. of water was observed once only. The standard error of one observation $=0.7$.
SUBJECTS STUdiED. - Twelve normal subjects with a mean age of 30 years and 12 with a mean age of 64 years were studied (Table I). They were male members of the medical and administrative staff of a city hospital and had no history or clinical evidence of respiratory disease.

TABLE I

RELATION BETWEEN GRADE OF DYSPNOEA, PEAK INTERRUPTER PRESSURE, AND VENTILATION AT REST INTERRUPTER PRESSURE, AND DURING EXERCISE IN 24 NORMALS
AND DUR

\begin{tabular}{|c|c|c|c|c|c|}
\hline Age & $\begin{array}{c}\text { Grade } \\
\text { of } \\
\text { Dys- } \\
\text { pnoea* }\end{array}$ & $\begin{array}{c}\text { Respi- } \\
\text { ratory } \\
\text { Rate }\end{array}$ & $\begin{array}{c}\text { Tidal } \\
\text { Volume } \\
\text { (litres) }\end{array}$ & $\begin{array}{l}\text { Ventilation } \\
\text { (1. min.) }\end{array}$ & $\begin{array}{l}\text { Peak Inspi- } \\
\text { ratory plus } \\
\text { Expiratory } \\
\text { Interrupter } \\
\text { Pressure } \\
\text { (cm. water) }\end{array}$ \\
\hline \multicolumn{6}{|c|}{12 Younger Normal Subjects } \\
\hline $\begin{array}{c}30 \\
(17-42)\end{array}$ & $\begin{array}{l}0 \\
1 \\
2\end{array}$ & $\left|\begin{array}{c}16 \\
(10-22) \\
20 \\
(16-25) \\
29 \\
(21-39)\end{array}\right|$ & $\begin{array}{c}0.75 \\
(040-1 \cdot 15) \\
1 \cdot 60 \\
(1.05-2 \cdot 40) \\
2.40 \\
(1.75-3.05)\end{array}$ & $\begin{array}{c}11 \cdot 9 \\
(7 \cdot 6-159) \\
31 \cdot 0 \\
(22 \cdot 0-45 \cdot 6) \\
68 \cdot 2 \\
(50 \cdot 2-109 \cdot 2)\end{array}$ & $\begin{array}{c}3 \cdot 8 \\
(2 \cdot 7-4 \cdot 8) \\
12 \cdot 2 \\
(10-14) \\
46 \\
(35-62)\end{array}$ \\
\hline \multicolumn{6}{|c|}{12 Older Normal Subj } \\
\hline $\begin{array}{c}64 \\
(48-76)\end{array}$ & $\begin{array}{l}0 \\
1 \\
2\end{array}$ & $\mid \begin{array}{c}16 \\
(8-26) \\
20 \\
(13-33) \\
26 \\
(16-37)\end{array}$ & $\begin{array}{c}0.67 \\
(0.41-095) \\
1.30 \\
(0.95-1.65) \\
1.80 \\
(1.15-2.50)\end{array}$ & $\begin{array}{c}10 \cdot 1 \\
(4 \cdot 6-15 \cdot 0) \\
25 \cdot 2 \\
(15 \cdot 0-31 \cdot 9) \\
45 \cdot 1 \\
(32 \cdot 8-66 \cdot 6)\end{array}$ & $\begin{array}{c}3 \cdot 3 \\
(2 \cdot 5-4 \cdot 0) \\
11 \cdot 0 \\
(9 \cdot 0-13 \cdot 0) \\
33 \cdot 4 \\
(19 \cdot 0-46 \cdot 0)\end{array}$ \\
\hline
\end{tabular}

The figures are the mean values with the ranges beneath in brackets. * Grades of dyspnoea : 0 - No dyspnoea, subject at rest. 1-Exercise to just detectable dyspnoea. 2-Exercise to maximum dyspnoea.

Twenty-six men with bronchitis and emphysema from a city population were studied while undergoing in-patient treatment for respiratory infections and subsequently during convalescence as out-patients. Twelve patients with a mean age of 63 years were assessed on clinical grounds as mildly or moderately affected and were examined at rest and during exercise (Table II); seven were also examined during

TABLE II

RELATION BETWEEN GRADE OF DYSPNOEA PEAK INTERRUPTER PRESSURE, AND VENTILATION AंT REST AND DURING EXERCISE IN 23 PATIENTS WITH
BRONCHITIS AND EMPHYSEMA

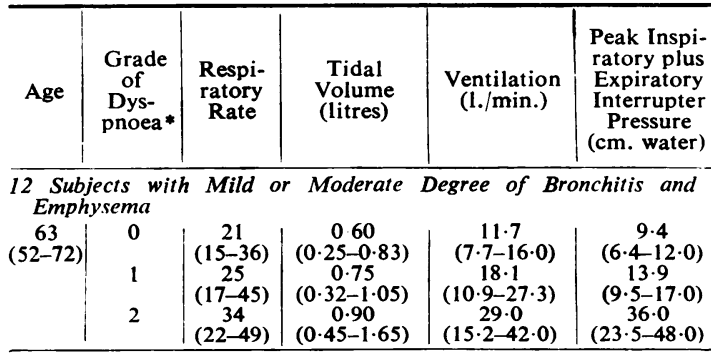

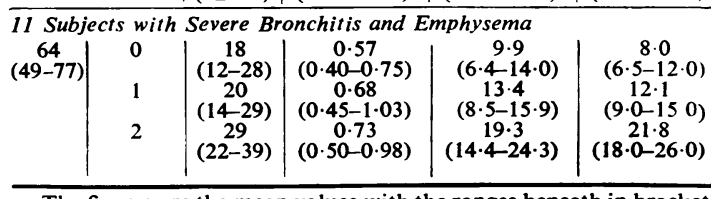

The figures are the mean values with the ranges beneath in brackets. to just detectable dyspnoea. 2-Exercise to maximum dyspnoea. 


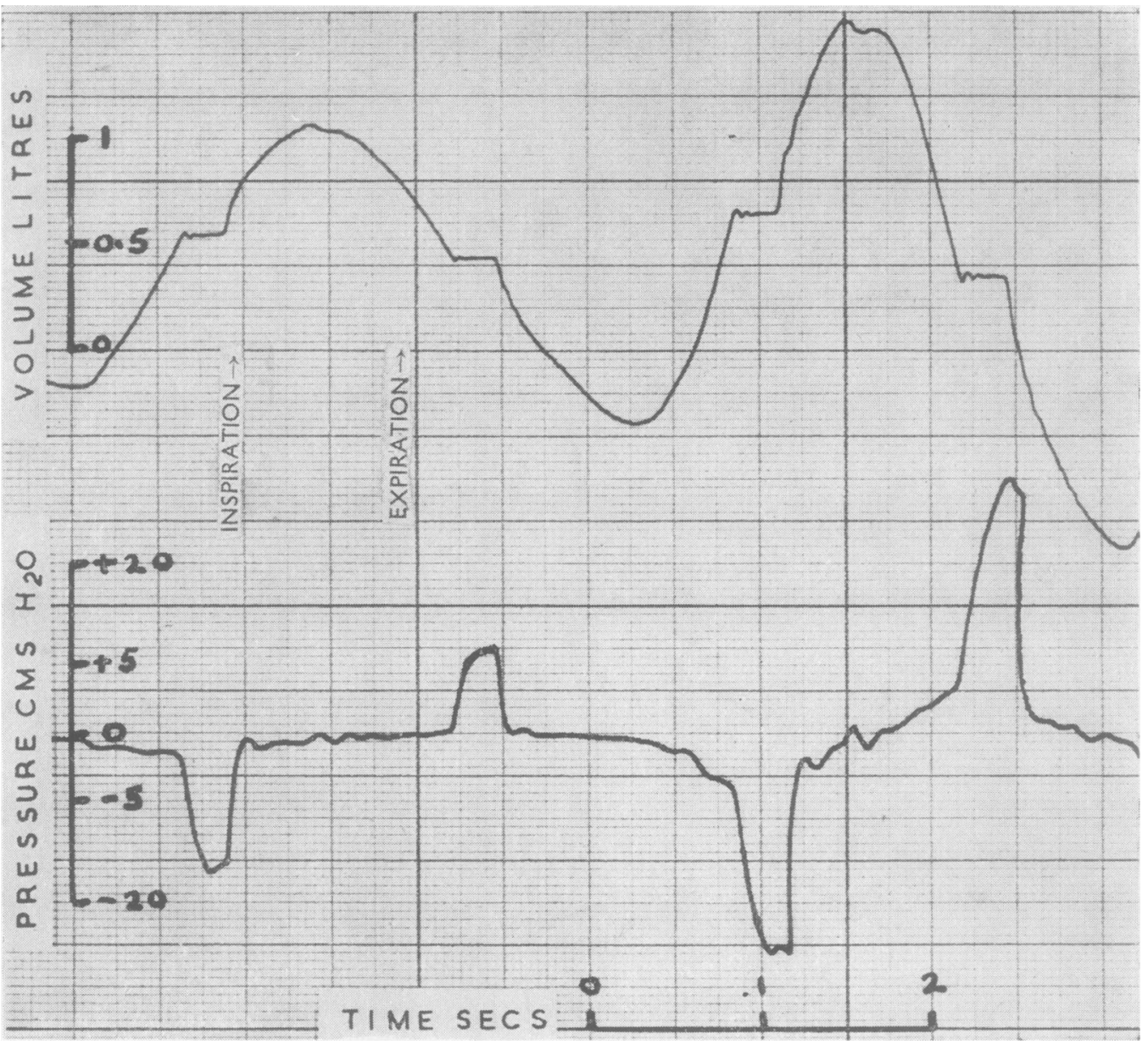

Fig. 3.-An Illusration of the spirographic tracing (above) and the interrupter pressure record (below) from a normal subject taking a moderately deep breath followed by a deeper breath.

respiratory infections (Table III). A further 14 patients with a mean age of 64 years were severely affected ; of these, eight developed cardiac failure and three died. Eleven were examined at rest and during exercise (Table II) and seven during respiratory infections (Table III).

Procedure.-Dyspnoea is defined in this paper as the sensation of difficult breathing. Its purely subjective nature makes its severity difficult to assess. The only levels which can be defined at all clearly are at each end of the range, namely just detectable dyspnoea and maximum dyspnoea. The interrupter pressures were therefore measured at these points whether dyspnoea was due to respiratory infection or to exercise. The possible effect on the results of defining dyspnoea in this way is discussed below.

Records of tidal volume, respiratory rate, and interrupter pressure were made in patients with acute exacerbations of chronic bronchitis shortly after admission to hospital. Whenever possible, observations were made when dyspnoea was greatest as a result of the disease process, during recovery when dyspnoea? was just detectable, and after recovery when thers
was none.

Control observations were made on normal sub jects and on patients who had recovered sufficientl to be ambulant as follows: (1) In the sitting position after resting for five minutes ; (2) after exercise on bicycle ergometer to just detectable dyspnoea; and (3) after exercise to the limit of tolerance. Dyspnoes appeared to be the limiting factor in all subjects when any other condition limited exercise, the re? sults were excluded from the series.

\section{RESULTS}

Relation between Dyspnoea and Peak In $\frac{\rho}{\mathbb{D}}$ spiratory to Peak Expiratory Pressure Changeo IN NoRmals at Rest aNd dURING ExERCISE.- No significant differences between the magnitude of 
TABLE III

RELATION BETWEEN GRADE OF DYSPNOEA, PEAK INTERRUPTER PRESSURE, AND VENTILATION IN PATIENTS DYSPNOEIC AT REST AS A RESULT OF RESPIRATORY INFECTIONS

\begin{tabular}{c|c|c|c|c|c}
\hline Age & $\begin{array}{c}\text { Grade } \\
\text { of } \\
\text { Dys- } \\
\text { pnoea* }\end{array}$ & $\begin{array}{c}\text { Respi- } \\
\text { ratory } \\
\text { Rate }\end{array}$ & $\begin{array}{c}\text { Tidal } \\
\text { Volume } \\
\text { (litres) }\end{array}$ & $\begin{array}{c}\text { Ventilation } \\
\text { (1. } / \text { min.) }\end{array}$ & $\begin{array}{c}\text { Peak Inspi- } \\
\text { ratory plus } \\
\text { Expiratory } \\
\text { Interrupter } \\
\text { Pressure } \\
\text { (cm. water) }\end{array}$ \\
\hline
\end{tabular}

7 Subjects with Mild and Moderate Bronchitis and Emphysema

\begin{tabular}{|c|c|c|c|c|c|}
\hline $\begin{array}{c}62 \\
(52-72)\end{array}$ & & $\mid \begin{array}{c}28 \\
(19-40) \\
41 \\
(25-54)\end{array}$ & $\begin{array}{c}0.53 \\
(0.35-0.78) \\
0.44 \\
(0.33-0.63)\end{array}$ & $\begin{array}{c}13.9 \\
(9.4-21.7) \\
17.1 \\
(13.9-20.0)\end{array}$ & $\begin{array}{c}13 \cdot 1 \\
(11 \cdot 0-16 \cdot 0) \\
24 \cdot 2 \\
(18 \cdot 0-36 \cdot 0)\end{array}$ \\
\hline
\end{tabular}

7 Subjects with Severe Bronchitis and Emphysema

\begin{tabular}{c|c|c|c|c|c}
65 & 65 & 24 & $0 \cdot 40$ & $9 \cdot 7$ & $10 \cdot 0$ \\
$(56-75)$ & 1 & $(20-34)$ & $(0 \cdot 35-0 \cdot 50)$ & $(7 \cdot 9-11 \cdot 9)$ & $(9 \cdot 0-11 \cdot 0)$ \\
& 2 & 42 & $0 \cdot 30$ & $12 \cdot 5$ & $14 \cdot 3$ \\
& & $(29-52)$ & $(0 \cdot 23-0 \cdot 35)$ & $(9 \cdot 4-18 \cdot 2)$ & $(12 \cdot 5-17 \cdot 0)$
\end{tabular}

The figures are the mean values with the ranges beneath in brackets. * Grades of dyspnoea: 1 -Respiratory infection producing just detectable dyspnoea. 2-Respiratory infection producing maximum dyspnoea.

† Three patients in this group died of the respiratory infection.

the inspiratory and expiratory interrupter pressures were noted in the normal subjects or patients studied and the result in each group is therefore expressed as the peak inspiratory to peak expiratory pressure change. The resting pressures are $3.8 \mathrm{~cm}$. and $3.3 \mathrm{~cm}$. water for the young and old groups respectively (Table I). On exercise, dyspnoea is just detectable at average values of 12.2 and $11 \mathrm{~cm}$. respectively and the pressures at the level of maximal dyspnoea are 46 and $33.4 \mathrm{~cm}$. Thus, the young group is capable of augmenting pressure by $42.2 \mathrm{~cm}$. compared with $30.1 \mathrm{~cm}$. in the old group. The mean value for pressure in the presence of maximal dyspnoea is significantly lower in the older group (difference $=12.6 \mathrm{~cm}$. ; $\mathrm{t}(22$ d.f.) $3.49 ; \mathrm{P}<0.01)$.

Relation between Dyspnoea and Peak Inspiratory to Peak Expiratory Pressure Change in PATIENTS With Bronchitis and EMPHysema at REST AND DURING EXERCISE.-Table II shows that in the mild and moderately severe cases the average pressure at rest is $9.4 \mathrm{~cm}$., which is more than double the normal value although the ventilation of the two groups does not differ significantly. On exercise, just detectable dyspnoea occurs at $13.9 \mathrm{~cm}$., which is not significantly different from the normal value, but occurs at a significantly lower ventilation, $18.1 \mathrm{l} . / \mathrm{min}$. (difference $=7.1 \mathrm{l}$.; t(17 d.f.) $3.005 ; 0.01>P>0.001)$. The average pressure at maximal dyspnoea is $36 \mathrm{~cm}$. and is again not significantly different from the normal value, but is at a ventilation (29 $1 . / \mathrm{min}$.) onethird less than normal (difference $=16.11$. ; $\mathrm{t}(22$ d.f.) $4.232 ; \mathrm{P}<0.001)$.
Severe cases (Table II) show the same general pattern as the milder group at rest and on exercise when dyspnoea is just detectable, but they become maximally dyspnoeic at a significantly lower pressure, $21.8 \mathrm{~cm}$. (difference $=14.2 \mathrm{~cm}$.; $\mathrm{t}(11$ d.f.) $5.90 ; \mathrm{P}<0.01$ ), and ventilation, 19.31 . $/ \mathrm{min}$. (difference $=9.71$. ; $t(21$ d.f.) $3.258 ; 0.01>P>0.001)$, than the less severe cases. The tables show clearly that the lower minute volumes in both groups are a consequence of the smaller tidal volumes.

It was observed that in severely disabled patients the severity of dyspnoea was less closely related to the severity of the exercise than in the normal subjects and seemed to have an "all or nothing "quality. That is to say, the patients were less able to distinguish degrees of breathlessness than the normal person. This can be related to the finding that the change from minimal to maximal levels of dyspnoea on exercise is associated with a diminished range of pressure. The phenomenon is most marked when exercise is attempted during exacerbations of infection, as described below.

Relation between Dyspnoea and Peak InSpiratory to Peak Expiratory Pressure Change DURING RESPIRATORY INFECTION. - Table III shows that just detectable dyspnoea due to disease when the patient is at rest occurs at a pressure of $13.1 \mathrm{~cm}$. in the milder group and $10 \mathrm{~cm}$. in the severe group. These pressures approximate fairly closely to those at the level of just detectable dyspnoea on exercise in normal subjects and convalescent patients but are associated with a smaller increase in ventilation above the resting level in the milder group and no significant increase in the severe group. Maximal dyspnoea during severe infections is associated with a pressure of $24.2 \mathrm{~cm}$. in the milder group and a significantly lower pressure of $14.3 \mathrm{~cm}$. in the severe group (difference= $9.9 \mathrm{~cm}$.; $\mathrm{t}(10$ d.f.) $3.72 ; \mathrm{P}<0.01)$, and with a significantly lower ventilation, $12.51 . / \mathrm{min}$. (differ ence $=4.61$. $; \mathrm{t}(10$ d.f.) $2.727 ; \mathrm{P} \bumpeq 0.02)$.

It may be objected that the patient's assessment of maximal dyspnoea could not, in fact, be correct and that further advance of the disease would lead to still greater dyspnoea, possibly producing a greater rise of pressure. But this objection applies with equal force to mild and severe cases and therefore does not explain the difference between them. Moreover, in several fatal cases, which were followed to their termination, no further rise of pressure could be detected. In fact. pressures were maintained at the impaired level until within three to four hours of death. During this period a slight further impairment of 1 to 
$3 \mathrm{~cm}$. preceded terminal interruption of rhythmical motor activity. This fall in pressure was associated with a fall in ventilation from about 12 to $8-91 . / \mathrm{min}$.

Thus, the change from minimal to maximal levels of dyspnoea is again associated with a smaller change of pressure in the severe group $(4.3 \mathrm{~cm}$.) than in the milder group $(11.1 \mathrm{~cm}$.). Moreover, the change is smaller in the severe group during respiratory infections $(4.3 \mathrm{~cm}$.) than on exercise $(9.7 \mathrm{~cm}$.). This may well be related to the much more marked "all or nothing" character of dyspnoea which the advanced cases exhibit during exacerbations of disease. Thus, by moving about in bed, the patient may reduce himself from a state of comparative comfort to one of marked distress, and this increase of dyspnoea is associated with only slight objective evidence of increased movement of the thoracic cage. This phenomenon is most marked during exacerbations of infection and for three to four weeks afterwards. Subsequently, in a number of instances, the pressures tended to increase, producing a return towards the normal relation between pressure and dyspnoea. These features occur especially in patients having a long history of severe respiratory disability and also when the current attack is of long duration.

\section{Discussion}

The mouth pressure developed during brief airway interruption is generally considered to be determined by the component of the respiratory muscular force required to overcome the airway and non-elastic tissue resistances of the lung (Mead and Whittenberger, 1954 ; Fry, Ebert, Stead, and Brown, 1954). Pressure will therefore diminish if the muscular force or the resistances diminish. In fact, in these patients the airway resistance increases (Dayman, 1951 ; Fry and others, 1954), and the tissue resistance may also increase, especially during respiratory infections (Marshall and Christie, 1954). It therefore appears likely that the lower pressure in subjects with advanced bronchitis and emphysema was due to a diminution in the muscular force. Uneven ventilation in emphysema has been shown to produce temporal as well as spatial differences in the distribution of gas flow in the various units of the lung and this factor might be considered likely to have rendered the interrupter pressure inaccurate by preventing the establishment of a plateau (Otis, McKerrow, Bartlett, Mead, McIlroy, Selverstone, and Radford, 1956). Satisfactory plateau formation was obtained, however, in these patients.
Two factors appear capable of leading to a re- $\frac{\overrightarrow{\vec{N}}}{\overrightarrow{0}}$ duction in the muscular force. In emphysematous patients, Fry and others (1954) have shown that the expiratory pressure-flow curve tends to $\overline{\bar{c}}$ reach an asymptote; an increase of pressure $\widehat{\Phi}$ beyond a certain level is seldom accompanied $\stackrel{\propto}{\rho}$ by an increase in flow and in fact may fall. ${ }^{\infty}$ Some preliminary observations on emphysema- $\vec{O}$ tous patients suggest that on account of this fac- $\vec{\overrightarrow{ }}$ tor, maximal ventilation at the limit of exercise ${ }_{\infty}^{\omega}$ tolerance is achieved at a lower pressure than that $\vec{F}$ required to produce maximal ventilation in nor- $x$ mal subjects. The reduction in force may there- $\vec{\omega}$ fore be in the nature of a reflex adjustment in $\overrightarrow{-}$ order to maintain maximum ventilatory efficiency.

Secondly, a diminished sensitivity of the respi-윽 ratory centre acquired during a prolonged respira- tory infection may result in an impaired response $?$ to the stimulus produced by this infection, or by⿳亠丷厂 exercise during convalescence. Patients with ${ }^{\supset}$ severe bronchitis and emphysema are known to $c$ have a diminished ventilatory response to inhala- 0 tion of carbon dioxide (Scott, 1920; Donald ando Christie, 1949 ; Tenney, 1954). The sensitivity of the respiratory centre to carbon dioxide has been shown to depend on the prevailing level of arterial@ carbon dioxide tension. In severe cases this levelब is raised and the ventilatory response diminishes with increasing levels of resting arterial carbon윽 dioxide tension (Prime and Westlake, 1954). The level tends to be raised especially during and after prolonged respiratory infections. Carbon dioxide is an important companent of the stimulus aug- $-\overrightarrow{\vec{\sigma}}$ menting the force of respiration during exercise, and a diminished sensitivity to it may there-ifore be expected to impair the maximal force developed during exercise in the convalescentio period.

The ventilatory response to maximal exercise iso diminished in patients with bronchitis and emphy sema, but no definite lowering of the peak oeso-o phageal pressures has been observed (Marshall and others, 1954 ; Ogilvie, Stone, and Marshallo 1955). The present results suggest that definiten differences between the mild and severe group of patients both in ventilation and in interruptero pressure become evident on exercise when they are examined after respiratory infections. Ventilatory and pressure differences between the two groups? were also observed when the patients were examined during the course of respiratory infec tions. The smaller tidal volumes observed in the severe group can be attributed partly to the greate $\overrightarrow{\mathbb{D}}$ airway and tissue resistances likely to have beeno present, but also to the smaller muscular forces 
available to meet these resistances. The latter factor is probably particularly important in the severe or fatal respiratory infections that are liable to occur in patients with advanced bronchitis and emphysema, because it contributes to the progressive impairment of alveolar ventilation that makes these infections so serious.

\section{SUMmaRY}

The peak inspiratory and expiratory pressures developed at the mouth during natural breathing have been measured by the airway interrupter method at rest, on exercise, and during respiratory infection. Ventilation was also measured. A group of mild and a group of severe cases of bronchitis and emphysema were studied and the results compared with those from young and old groups of normal subjects.

Patients suffering from severe bronchitis and emphysema were found to develop significantly lower pressures during respiratory infections and on maximum exercise than normal subjects, especially after prolonged infections. Ventilation was also diminished and this was due almost entirely to smaller tidal volumes. In fatal cases, peak pressures and tidal volumes progressively diminished in the terminal stages of the disease.
The relation between dyspnoea and pressure was examined. The change in degree of breathlessness during a respiratory infection or on exercise, from the level of just detectable dyspnoea to that of maximal dyspnoea, was associated with a smaller increase of pressure in the very breathless than in the less severely disabled and normal subject.

I wish to thank Dr. B. Gottlieb and Dr. F. J. Prime for valuable advice and criticism during the course of this work.

\section{REFERENCES}

Bernstein, L., D'Silva, J. L., and Mendel, D. (1952). Thorax, 7, 255. Cht istie, R. V. (1953). Proc. roy. Soc. Med., 46, 381.

Dayman, H. (1951). J. clin. Invest., 30, 1175.

Donald, K. W., and Christie, R. V. (1949). Clin. Sci., 8, 33.

Fry, D. L., Ebert, R. V., Stead, W. W., and Brown, C. C. (1954). Amer. J. Med., 16, 80.

Marshall, R., and Christie, R. V. (1954). Clin. Sci., 13, 403.

Stone, R. W., and Christie, R. V. (1954). Ibid., 13, 625.

Mead, J., and Whittenberger, J. L. (1954). J. appl. Physiol., 6, 408. Neergaard, K. von, and Wirz, K. (1927). Z. klin. Med., 105, 51.

Ogilvie, C. M., Stone, R. W., and Marshall, R. (1955). Clin. Sci., $14,101$.

Otis, A. B., and Proctor, D. F. (1948). Amer. J. Physiol., 152, 106. - McKerrow, C. B., Bartlett, R. A., Mead, J., McIlroy, M. B. Selverstone, N. J., and Radford, E. P. (1956). J. appl. Phvsiol., $8,427$.

Prime, F. J., and Westlake, E. K. (1954). Clin., Sci., 13, 321.

Scott, R. W. (1920). Arch. intern. Med., 26, 544.

Tenney, S. M. (1954). J. appl. Physiol., 6, 477.

Vuilleumier, P. (1944). Z. klin. Med., 143, 698.

Westlake, E. K. (1954). Brit. med. J., 2, 1012. 